\title{
Sustained arm visiting by nondeprived, nonrewarded rats in a radial maze
}

\author{
DONALD M. WILKIE, DAVE G. MUMBY, GARY NEEDHAM, and MICHAEL SMEELE \\ University of British Columbia, Vancouver, British Columbia, Canada
}

\begin{abstract}
Nondeprived rats were tested in an empty eight-arm radial maze. The rats persisted in visiting empty arms over a prolonged period (over 30 days). The rats entered the arms in a nonrandom pattern, a result that suggests that subjects remembered and avoided arms they had recently visited. These results, and others in the literature, suggest that sustained, nonrandom exploration of the environment is a basic behavior of rats.
\end{abstract}

Olton and Samuelson (1976) first described the behavior of hungry rats in the elevated radial-arm maze. The maze consisted of a central platform from which eight arms radiated, like spokes on a wheel. The distal end of each arm contained a small cup that was baited with a small piece of food. Rats placed on the maze quickly became very proficient at collecting the eight pieces of food, rarely revisiting depleted arms. This proficiency at collecting food was initially attributed to a species-specific "winshift" foraging strategy (e.g., Olton \& Schlosberg, 1978). Other more recent research, in particular studies by FitzGerald, Isler, Rosenberg, Oettinger, and Bättig (1985) and Timberlake and White (1990), has offered alternative interpretations.

In one part of their study, FitzGerald et al. (1985) tested both food-deprived and nondeprived rats in a variant of a six-arm radial maze. The maze had enclosed alleys that were $8 \mathrm{~cm}$ wide and $15 \mathrm{~cm}$ high. The alleys were Mshaped and forced the rats to make a right-, a left-, and then another right-hand turn to reach the end of the arm. Food (for the deprived rats) was located at the end of each arm. Interestingly, FitzGerald et al. found essentially no difference in the behavior of the deprived and nondeprived rats. Both groups of rats visited the food bait locations and made equal numbers of "errors" (i.e., revisits to a previously visited arm). FitzGerald et al. concluded that a spontaneous tendency to avoid recently visited places, rather than a win-shift feeding strategy, was the major determinant of their rats' behavior in the radial maze.

Timberlake and White (1990) tested three groups of rats in an elevated, enclosed radial maze that had eight $10 \times 70$ $\mathrm{cm}$ arms, the sidewalls of which were $3 \mathrm{~cm}$ and $12 \mathrm{~cm}$ tall. One group of rats was not deprived of food; for these rats the maze was devoid of food. Two other groups of

\footnotetext{
This research was supported by grants from the Natural Sciences and Engineering Research Council of Canada. Michael Tan and Chee Siah Chang assisted with data collection. Rob Willson provided several helpful comments on the manuscript. Send all correspondence regarding this article to D. M. Wilkie, Department of Psychology, The University of British Columbia, 2136 West Mall, Vancouver, BC V6T 1Z4, Canada (e-mail:wilkie@unixg.ubc.ca).
}

rats were deprived of food and were maintained at $85 \%$ of normal body weight. For one of these groups, each arm of the maze was baited with food. The third group, like the first, was tested in a nonbaited maze. The deprived, rewarded rats behaved as many other rats have in similar conditions: they efficiently traversed the maze and collected the pieces of food, and in doing so rarely revisited depleted arms. Interestingly, the behavior of the deprived, nonrewarded rats was indistinguishable from that of the deprived, rewarded rats. This group of rats also efficiently traversed the maze, rarely revisiting arms. Because this pattern of behavior was not observed in the nondeprived, nonrewarded rats (but see later discussion), Timberlake and White suggested that the state of food deprivation releases preorganized foraging strategies, such as the tendency to avoid recently visited locations.

The experiment reported here was an extension of the FitzGerald et al. (1985) study. The main way our experiment differed from theirs, apart from the fact that we used a different variant of the radial maze, was that we tested our nondeprived, nonrewarded rats for an extended period of time (32 days). FitzGerald et al. tested their rats for 6 days. We were interested in determining if the rats' arm-visiting behavior would persist over longer periods. Intuitively, one might expect that nondeprived, nonrewarded rats, tested in a nominally static environment, would eventually stop visiting arms. On the other hand, there is considerable evidence, from both laboratory and field studies, that rodents regularly, and systematically, patrol their home ranges (e.g., Barnett, Dickson, Marples, \& Radha, 1978; Cowan, 1977, 1983). On the basis of that literature, one might predict no diminution in the frequency of arm visiting.

\section{Method}

\section{Subjects}

The subjects were 12 150-day-old, male Long-Evans rats. The subjects were group housed in suspended wire-mesh cages in a climatecontrolled colony (about $20^{\circ} \mathrm{C}$ ) maintained on a 12:12-h light:dark cycle. The subjects had continuous free access to water and Purina Rat Chow except for the brief period of behavioral testing each day. The subjects were tested in the middle to later part of the dark phase of the diurnal cycle. 

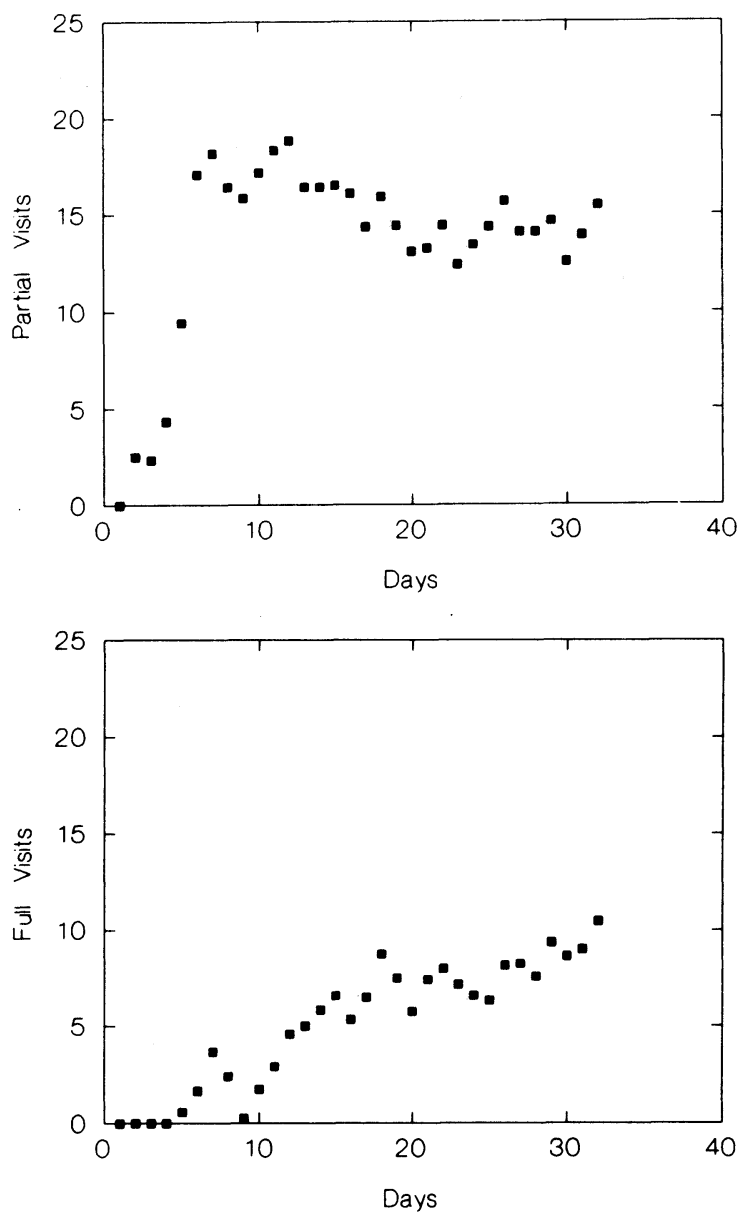

Figure 1. Arm visits by rats during 32 days.

\begin{abstract}
Apparatus
The eight-arm radial maze was elevated $37 \mathrm{~cm}$ above the floor. The central area of the maze measured $87 \mathrm{~cm}$ in diameter and was surrounded by a 30 -cm-high wall in which eight $7 \times 5 \mathrm{~cm}$ doorways had been cut, providing unobstructed access to each of the arms. The arms, which did not have walls, were $15 \mathrm{~cm}$ wide and $30 \mathrm{~cm}$ long. Each arm was visually isolated from the others by a $37 \times 37 \mathrm{~cm}$ panel attached to the central vertical wall of the maze. The floor of the maze was gray, the central vertical wall was blue, and the panels were orange. The maze was located near the center of a $3 \times 3 \times 3 \mathrm{~m}$ room, one wall of which had a counter and shelves. Another wall had a door. A tripod-mounted camcorder was located in the corner between the other two walls. Illumination was provided by banks of fluorescent lights on the ceiling.

\section{Procedure}

Each subject was placed on the maze for $10 \mathrm{~min}$ on each of 32 consecutive days. The rat was placed in the central area of the maze and was oriented in a random direction with respect to the eight arms. The experimenter observed the rat during the 10 -min period and made a record of two types of arm entries. A partial entry was recorded when a rat's forelimbs passed through the threshold of the doorway. A full entry was recorded when a rat's hind limbs passed over the threshold.
\end{abstract}

\section{RESULTS}

Figure 1 shows the average number of partial and full arm entries made by the rats over the course of the experiment. On the first day of the experiment, none of the rats ventured into any of the arms; all rats spent the entire 10-min session investigating the central area of the maze. Thereafter, the number of partial entries increased rapidly. The number of full visits increased more slowly and reached a much lower level. There is some evidence in Figure 1 that the number of full entries had still not reached asymptote after 32 days of exposure to the maze. In any case, the data shown in Figure 1 unambiguously demonstrate the persistence with which nondeprived, nonrewarded rats visit different locations. This behavioral characteristic was previously described by FitzGerald et al. (1985), but only for a period of 6 days. The present observations show that this pattern of behavior persists over prolonged periods of time and might never diminish.

Figure 2 shows the proportion of arm entries (both partial and full) that were revisits. There, data were calculated from the first eight visits during Sessions 6-32. If the subjects visited arms in a completely random pattern, .344 of all visits would be revisits. The proportion of revisits was considerably less than this number, suggesting that the rats were using some strategy such as spatial memory to avoid reentering previously visited arms. The data displayed in Figure 2 were analyzed statistically by a onesample $t$ test that compared each rat's average performance to chance. This test revealed that the proportion of revisits was significantly different from chance $[t(11)=$ $-13.20, p<.0001]$.

\section{DISCUSSION}

A novel finding in the present experiment concerned the persistence of arm-visiting behavior by nondeprived, nonrewarded rats. We observed no diminution in the number of arm visits in more than a month of daily 10-min tests. Indeed, when we looked at complete as opposed to partial arm entries, there was a suggestion that this behavior might still have been increasing after 30 days of testing. Many rodents readily habituate to objects in their environments and cease exploring them after periods as short as several minutes (e.g., Poucet, Durup, \& Thinus-Blanc, 1988). However, it seems that rats do not "habituate" to spatial locations, at least in visiting radial-maze arms. Overall, our data are consistent with Cowan's (1983) statement that sustained, organized "patrolling" of environments seems to be a fundamental characteristic of rat behavior.

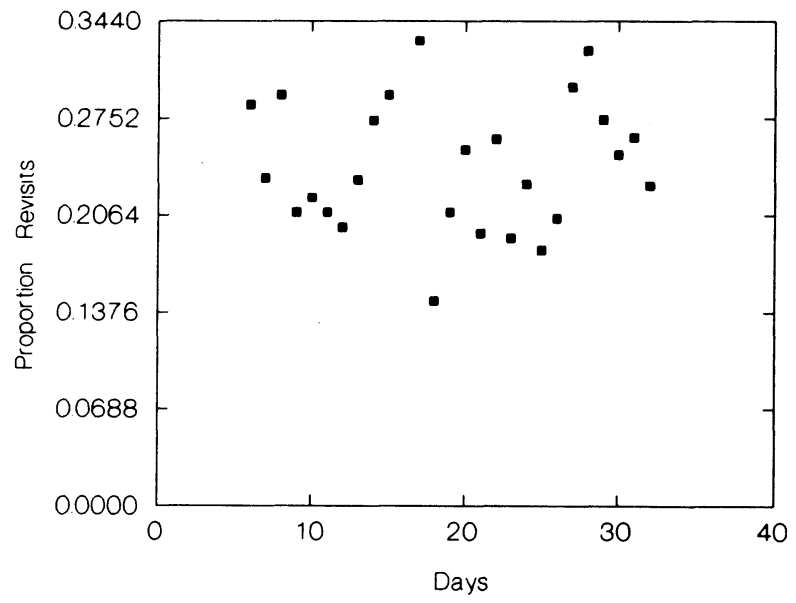

Figure 2. Proportion of arm visits that were revisits. 
The pattern of arm visits by nondeprived, nonrewarded rats seems to be at least somewhat organized; the rats make fewer revisits than expected from simple random arm selection. Given the wealth of evidence in the radial-maze literature that rats use spatial memory to avoid visiting arms that have been previously visited, this process would be a good candidate for the mechanism by which our rats avoided revisits. On the surface, these revisit data appear to be at odds with those of Timberlake and White (1990). Recall that these authors reported that their nondeprived, nonrewarded rats visited novel arms at a rate that was not significantly different from chance. Although this was certainly true statistically, there was a definite trend for these rats, like ours, to avoid previously visited arms. The mean performance of their nondeprived, nonrewarded rats differed from chance in six out of eight blocks of three sessions (see Timberlake \& White's Figure 1). It should also be pointed out that their sample size $(N=5)$ was smaller than ours $(N=12)$; statistical power may be an important factor.

It is important to note that our rats, while making fewer errors than one would expect on the basis of random arm selection, did not reach the same low rate of revisiting arms that deprived and rewarded rats typically do. It may be the case that motivational and reward processes play a role in potentiating an apparent preorganized tendency on the part of rats to visit different locations in their environments.

\section{REFERENCES}

Barnett, S. A., Dickson, R. G., Marples, T. G. \& Radha, E.(1978). Sequences of feeding, sampling, and exploration by wild and laboratory rats. Behavioural Processes, 3, 29-43.
Cowan, P. E. (1977). Systematic patrolling and orderly behaviour of rats during recovery from deprivation. Animal Behaviour, 25, 171-184.

CowaN, P. E. (1983). Exploration in small mammals: Ethology and ecology. In J. Archer \& L. I. A. Birke (Eds.), Exploration in animals and humans (pp. 147-175). Cambridge: Van Nostrand Reinhold.

FitzGerald, R. E., Isler, R., Rosenberg, E., Oettinger, R., \& BÄTtIG, K. (1985). Maze patrolling by rats with and without food reward. Animal Learning \& Behavior, 13, 451-462.

Olton, D. S., \& SAmuelson, R. J. (1976). Remembrance of places passed: Spatial memory in rats. Journal of Experimental Psychology: Animal Behavior Processes, 2, 97-116.

Olton, D. S., \& Schlosberg, P. (1978). Food searching strategies in young rats: Win-shift predominates over win-stay. Journal of Comparative \& Physiological Psychology, 92, 609-618.

Poucet, B., Durup, B., \& Thinus-Blanc, T. (1988). Short-term and long-term habituation of exploration in rats, hamsters, and gerbils. Behavioural Processes, 16, 203-211.

TimberlaKe, W., \& White, W. (1990). Winning isn't everything: Rats need only food deprivation and not food reward to efficiently traverse a radial arm maze. Learning \& Motivation, 21, 153-163.

(Manuscript received February 24, 1992.) 